\title{
Implication of D2-like dopaminergic receptors in the median eminence during the establishment of long-day inhibition of $\mathrm{LH}$ secretion in the ewe
}

\author{
F Bertrand, J-C Thiery, S Picard and B Malpaux \\ Institut National de la Recherche Agronomique, URA Centre National de la Recherche Scientifique 1291, Laboratoire de Neuroendocrinologie Sexuelle, \\ 37380 Nouzilly, France \\ (Requests for offprints should be addressed to B Malpaux, INRA-PRMD, Laboratoire de Neuroendocrinologie Sexuelle, 37380 Nouzilly, France; \\ Email: malpaux@tours.inra.fr)
}

\begin{abstract}
In ewes, photoperiod modulates $\mathrm{LH}$ release and dopaminergic terminals in the median eminence (ME) have a critical role in the establishment of long-day inhibition of LH secretion. This study was undertaken to determine the type of dopaminergic receptors, D1-like or D2-like, that mediate the action of dopamine on $\mathrm{LH}$ secretion at the ME level in this situation. This was assessed, in ovariectomized and estradiol-treated ewes, with the use of reverse microdialysis in the $\mathrm{ME}$ in three experiments: first, when $\mathrm{LH}$ secretion was stimulated by short days, by determining the response to three doses $(0 \cdot 01,0 \cdot 1 \mathrm{or} 1 \mathrm{mg} / \mathrm{ml})$ of a D1-like (SKF38393) and a D2-like (quinpirole) agonist; secondly, during early long-day inhibition of LH secretion, by determining the ability of SKF38393 and quinpirole $(1 \mathrm{mg} / \mathrm{ml})$ to mimic the inhibitory effects of dopamine, after a blockade of its synthesis with $\alpha$-methyl-paratyrosine ( $\alpha$ MPT; $2 \mathrm{mg} / \mathrm{ml}$ ); and thirdly, during early long-day inhibition of LH secretion, by determining the response to three doses $(0.009,0.09$ or $0.9 \mathrm{mg} / \mathrm{ml})$ of a D1-like (SCH23390) and a D2-like (sulpiride) antagonist.

In none of the conditions was effect of the D1-like analogs on LH secretion found, compared with the control treatments. In contrast, the D2-like analogs caused changes in LH secretion. First, with short days, quinpirole in the highest dose significantly reduced mean LH concentration $(P<0 \cdot 05)$ and LH pulse frequency $(P<0 \cdot 01)$. Secondly, with long days, addition of quinpirole to $\alpha \mathrm{MPT}$ caused a significant decrease in LH secretion relative to $\alpha \mathrm{MPT}$ alone $(P<0 \cdot 05)$. Thirdly, with long days, sulpiride at the highest dose significantly increased mean LH concentration (during the first $3 \mathrm{~h}$ of treatment, $P<0 \cdot 05$ ) and $\mathrm{LH}$ pulse frequency $(P<0 \cdot 05)$. Prolactin secretion was also determined in these experiments, and D2-like agonist and antagonist caused an inhibition and a stimulation of prolactin secretion, respectively. These results demonstrate that, in the ME, inhibitory action of dopamine on LH secretion, critical for the initiation of long-dayinduced inhibition, is mediated by D2-like, not D1-like, dopaminergic receptors.

Journal of Endocrinology (1999) 163, 243-254
\end{abstract}

\section{Introduction}

In ewes, photoperiod controls reproductive activity by regulating the pulsatile secretion of luteinizing hormone (LH) (Karsch et al. 1984). In ovariectomized and estradioltreated $(\mathrm{OVX}+\mathrm{E})$ ewes, long days inhibit luteinizing hormone ( $\mathrm{LH}$ ) secretion after 20-30 days of exposure, whereas short days stimulate it after 40-60 days. These photoperiodically mediated changes in $\mathrm{LH}$ secretion reflect a shift in response of the LH-releasing hormone (LHRH) pulse generator to estradiol negative feedback, which constitutes a primary neuroendocrine mechanism for seasonal changes in ovarian cyclicity (Legan \& Karsch 1980). Photoperiodic information is transduced to the brain through the circadian rhythm of melatonin secretion. The neuroendocrine mechanism lying downstream from melatonin action and leading to regulation of LHRH and, consequently, of LH secretion, appears to involve several dopaminergic structures of the hypothalamus, such as A14 and A15 nuclei of the lateral retrochiasmatic area (Thiéry et al. 1989, Havern et al. 1994, Viguié et al. 1996), or the arcuate nucleus-median eminence (ME) region (Anderson et al. 1997, Bertrand et al. 1998, Viguié et al. 1998).

The ME dopaminergic terminals, which are located in the external layer of the ME (Tillet \& Thibault 1989), establish synaptic contacts with LHRH terminals, suggesting the possibility of a presynaptic control of LHRH secretion by dopamine (Kuljis \& Advis 1989). Several arguments suggest that these terminals are implicated in one of the final steps of the long-day-induced inhibition of LH secretion. Indeed, ME dopamine content and tyrosine hydroxylase (rate-limiting enzyme of the catecholamine 
biosynthesis) activity are lower under short days (high LH secretion) than under long days (low LH secretion; Thiéry 1991, Viguié et al. 1996, 1997). Importantly, blockade of dopamine synthesis in the ME, by local infusion of $\alpha$-methyl-para-tyrosine ( $\alpha \mathrm{MPT}$, a competitive tyrosine hydroxylase inhibitor) induces a stimulation of $\mathrm{LH}$ secretion in long day-inhibited OVX+E ewes (Viguié et al. 1998). It is noteworthy that this effect of $\alpha \mathrm{MPT}$ is observed during short-term long-day inhibition (30-40 days), but is no longer found in the longer term (70 days), strongly suggesting that an increased tyrosine hydroxylase activity in the ME is critical only during the establishment of the response (Bertrand et al. 1998).

An important step in the unraveling of the mechanisms of dopamine action during the establishment of the longday inhibition of LH secretion is the identification of the type of receptors mediating the action of dopamine, and thus the possibility of locating them at a cellular level. The action of dopamine can be mediated by two major types of dopaminergic receptors, D1-like and D2-like (Kebabian \& Calne 1979). Although the implication of D2-like receptors in the control of $\mathrm{LH}$ secretion has been shown in several physiological conditions in sheep (Meyer \& Goodman 1985, Curlewis et al. 1991, Havern et al. 1991, Anderson et al. 1997), the nature of the receptors involved in the ME is not known. Indeed, effects on LH secretion of D2-like receptor analogs delivered in the ME were observed, but dose-dependent comparisons of the effects of specific analogs of each type of receptor have not been performed in this site. In addition, because a high tyrosine hydroxylase activity is critical only during the establishment of the long-day inhibition, dopaminergic-specific neural mechanisms may be involved only during this stage of the response (Bertrand et al. 1998). It is therefore important to identify the type of receptors functionally important in the ME, and it is critical to perform this identification during the establishment of the long-day response. For this, the effects on $\mathrm{LH}$ secretion, used as an index of LHRH secretion, of D1-like and D2-like agonists (after blockade of dopamine synthesis) and antagonists infused locally in the ME were studied in OVX+E ewes exposed to 30-50 long days, when ME dopamine has been shown to be critical for the inhibition of LH secretion (Bertrand et al. 1998). Because prolactin (PRL) secretion is strongly regulated by photoperiod (Thimonier et al. 1978) and dopamine is involved in this regulation (Curlewis 1992), the effects of the different treatments on PRL secretion were also assessed.

\section{Materials and Methods}

\section{General}

These studies were performed at the Institut National de la Recherche Agronomique Research Center of Nouzilly, France. They were conducted on adult Ile de France ewes, maintained in photoperiod-controlled rooms under an artificial light regimen, alternating periods of constant long day (16 h light : $8 \mathrm{~h}$ darkness) and constant short day $(8 \mathrm{~h}$ light : $16 \mathrm{~h}$ darkness). Animals were fed with a standard diet of concentrate and straw and had free access to water. All animal procedures and care were performed in accordance with Authorization A37801 of the French Ministry of Agriculture.

The experiments consisted in assessing the effects of D1-like and D2-like specific dopaminergic analogs on LHRH secretion, estimated by LH secretion, using reverse microdialysis in the ME, in animals at the beginning of the long-day inhibition (30-50 days of long-day exposure). Two approaches were used. The aim of Experiment $1 \mathrm{~b}$ was to block dopamine synthesis in the ME by infusion of aMPT and to test the ability of a D1-like or D2-like agonist to restore the effects of dopamine on LH secretion. As it was difficult to determine the appropriate dose of agonist with such a procedure, a preliminary experiment (Experiment 1a) was carried out on short-day-stimulated ewes, to assess which agonist and what dose was able to inhibit LH secretion. The principle of the second experiment (Experiment 2) was to infuse a D1-like or D2-like antagonist in three doses to determine which was able to stimulate LH secretion. All the drugs were purchased from RBI (Sigma-Aldrich Chimie, Saint Quentin Fallavier, France).

\section{Animal model}

The animal model we used was the OVX $+\mathrm{E}$ ewe, bearing subcutaneous estradiol Silastic implants as described previously (Legan et al. 1977). For each experiment, ewes were ovariectomized at least 6 weeks before the microdialysis sessions and at the same time implanted with two subcutaneous Silastic estradiol implants of 0.5 and $1.5 \mathrm{~cm}$ length. This dose of estradiol was maintained before the microdialysis sessions, during the photoperiodic preparation of the animals. For the pharmacological challenges, the dose of estradiol was reduced by removing the $1.5 \mathrm{~cm}$ implant $72 \mathrm{~h}$ before microdialysis session, leaving the $0.5 \mathrm{~cm}$ implant in place. This model has been discussed previously (Bertrand et al. 1998).

\section{Design of experiment 1 a}

Seven OVX $+E$ ewes (Nos 1-7) were placed in a photoperiod-controlled room on September 8th. They were exposed to 84 long days followed by 78 short days before the beginning of the experiment, to stimulate $\mathrm{LH}$ secretion (Fig. 1). At this time, on three consecutive days, animals were infused in the ME with SKF38393 (specific D1-like agonist), quinpirole (specific D2-like agonist) or vehicle (Ringer's lactate). SKF38393 was dissolved in Ringer's lactate and quinpirole was dissolved first in $\mathrm{HCl}$ $0 \cdot 1 \mathrm{~N}$, then diluted nine times in Ringer's lactate and $\mathrm{pH}$ 
Photoperiodic treatments

EXPERIMENT 1a $(n=7)$

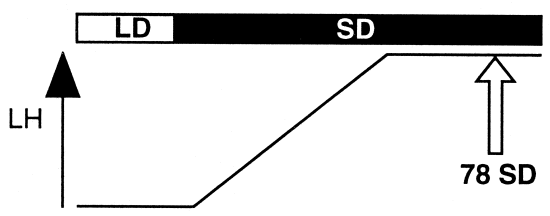

EXPERIMENT 1b $(n=12)$

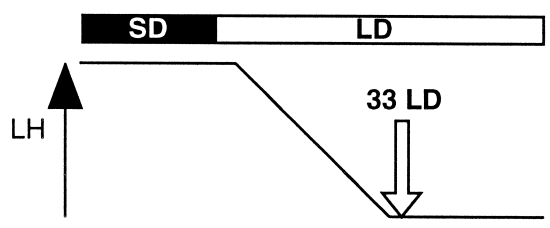

EXPERIMENT 2 ( $n=6)$

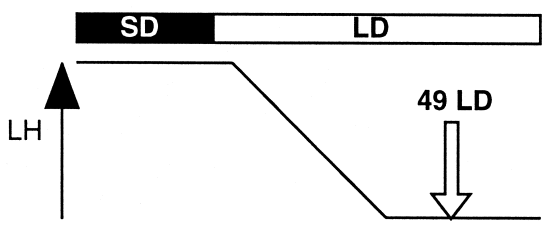

Microdialysis sessions designs
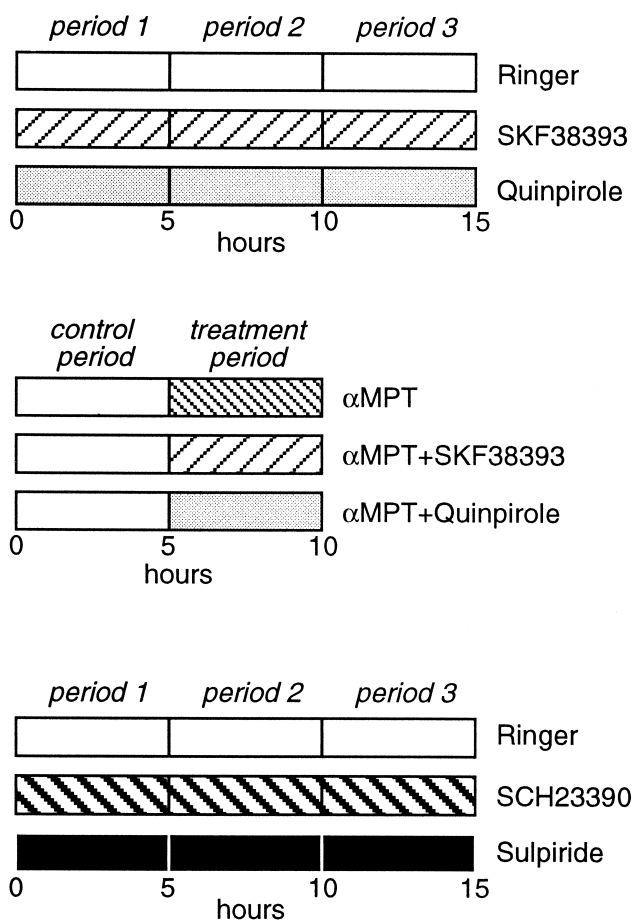

Figure 1 Experimental designs. Left panels: Photoperiodic treatments and theoretical time-course of mean $\mathrm{LH}$ concentration in $\mathrm{OVX}+\mathrm{E}$ ewes. Arrows indicate the beginning of the reverse microdialysis sessions. Right panels: Reverse microdialysis sessions designs. For each experiment, the sessions were performed on three consecutive days, with the order of the treatments randomized for each animal. Blood samples were collected every $10 \mathrm{~min}$. For Experiment 1a and Experiment 2, the dose of dopaminergic analogs was increased 10 times at the end of period 1 and period 2. (See text for details.)

was finally adjusted by adding $\mathrm{NaOH} 0 \cdot 1 \mathrm{~N}$. The ewes received one treatment each day, and the order of the three treatments was chosen according to a latin square design, in order to control experiment-duration and treatment-order effects. On each day, reverse microdialysis was performed for $15 \mathrm{~h}$ (beginning at $0930 \mathrm{~h}$ ), divided for both D1-like and D2-like agonist treatments in three periods of $5 \mathrm{~h}$, during which increasing successive doses were infused $(0 \cdot 01,0 \cdot 1$ and $1 \mathrm{mg} / \mathrm{ml})$. On the control day, animals were infused with Ringer's lactate for $15 \mathrm{~h}$ (Fig. 1).

\section{Design of experiment $1 \mathrm{~b}$}

Nine OVX+E ewes (Nos 11-19) were placed in a photoperiod-controlled room on July 1 st and were exposed to 88 short days. Three additional animals (Nos 8-10) were placed in a photoperiod-controlled room on November 15th and were exposed to 70 long days, followed by 68 short days. After short-day exposure, all the animals were submitted to 33 long days before the start of the experiment (Fig. 1). At this time, they were submitted, over three consecutive days, to three pharmacological treatments: infusion (in the ME) of $\alpha \mathrm{MPT}$ (2 mg/ml) alone, $\alpha$ MPT+SKF38393, or $\alpha \mathrm{MPT}+$ quinpirole. The dose for the agonists was $1 \mathrm{mg} / \mathrm{ml}$, as this dose of quinpirole was shown to be effective in Experiment 1a. $\alpha \mathrm{MPT}$ and $\alpha \mathrm{MPT}+\mathrm{SKF} 38393$ were dissolved in Ringer's lactate and $\alpha \mathrm{MPT}+$ quinpirole were dissolved in the same way as quinpirole in Experiment 1a. The ewes received one treatment each day, and the order of the three treatments was chosen according to a latin square design, in order to control experiment-duration and treatmentorder effects. Microdialysis sessions lasted $10 \mathrm{~h}$ (beginning at $0900 \mathrm{~h}$ ), with a 5-h control period (infusion of vehicle Ringer's lactate), followed by $5 \mathrm{~h}$ of pharmacological treatment (Fig. 1).

\section{Design of experiment 2}

Six ewes (Nos 20-25) were placed in a photoperiodcontrolled room on December 24th and were exposed to 75 long days, followed by 76 short days. Animals were then exposed to 49 long days before the experiment 
(Fig. 1). At this time, they were submitted to the same design as in Experiment 1a, but with two antagonists, SCH23390 (specific D1-like antagonist) and sulpiride (specific D2-like antagonist) at the doses of 0.009, 0.09 and $0.9 \mathrm{mg} / \mathrm{ml}$ (Fig. 1). SCH23390 was dissolved in Ringer's lactate and sulpiride was dissolved in the same way as quinpirole in Experiment 1a.

\section{Surgical access to the $M E$ and microdialysis sessions}

At least 1 month before microdialysis, animals were implanted with a stainless-steel guide cannula (external diameter $1.2 \mathrm{~mm}$; internal diameter $0.8 \mathrm{~mm}$; length $55 \mathrm{~mm}$ ) aimed toward the ME according to a surgical procedure described previously (Viguie et al. 1998). The site targeted was located $1 \mathrm{~mm}$ in front of the tip of the infundibular recess, $1 \mathrm{~mm}$ below the third ventricle floor and $0 \cdot 8-1 \mathrm{~mm}$ from the midline. The cannula was implanted with an angle of $6^{\circ}$ with respect to the sagittal plane, in order to avoid crossing the sagittal sinus and perfusing the drugs within the third ventricle. The tip of the guide cannula was $6 \mathrm{~mm}$ above the site. At the end of the surgery, a stainless-steel stylet of the length of the cannula was placed in the cannula; it was removed at the time of insertion of the probe, before the beginning of the microdialysis session.

The day before microdialysis, animals were placed in individual pens, and a polyethylene catheter was inserted in the jugular vein. At least $12 \mathrm{~h}$ before the beginning of the pharmacological challenge, the microdialysis probe was inserted in the guide cannula and infused with Ringer's lactate at a slow rate $(0.5 \mu \mathrm{l} / \mathrm{min})$ overnight. The probes were built according to a procedure described previously (Robinson \& Whishaw 1988), with an active membrane length of $3 \mathrm{~mm}$.

About $1 \mathrm{~h}$ before the first blood sample on the first day of the experiment, the flow rate was increased to $1 \mu \mathrm{l} / \mathrm{min}$. Between two days of dialysis, probes were left in place and infused overnight with Ringer's lactate. Drugs were dissolved just before the beginning of the experiments. Blood samples $(10 \mathrm{~min})$ were collected into heparinized tubes, centrifuged, and the plasma removed for later RIA to assess the effect of the drugs on LH and PRL secretion.

\section{Histological processing of the brains}

Ewes were killed, with their probes left in place, one day after the end of microdialysis treatment. Brains were processed according to a procedure described previously, to locate the position of the microdialysis probes within the

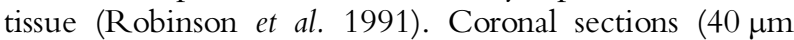
thick) of the hypothalamic block containing ME were collected and stained with cresyl violet acetate as described previously (Klüver \& Barrera 1953).

\section{Hormonal assays}

All the samples from one experiment were assayed in the same RIA. LH was assayed in duplicate $100 \mu \mathrm{l}$ aliquots of plasma using the RIA of Pelletier et al. (1968) modified by Montgomery et al. (1985). Sensitivity (2 S.D. from buffer controls) was $0 \cdot 1 \mathrm{ng} / \mathrm{ml} 1051-\mathrm{CY}-\mathrm{LH}(0 \cdot 2 \mathrm{ng} / \mathrm{ml}$ NIH-LH-S1). The intra-assay coefficient of variation (CV) for three plasma pools averaged 16\%. PRL was assayed in duplicate $10 \mu \mathrm{l}$ aliquots of plasma using the RIA of Kann (1971). Sensitivity was $8.5 \mathrm{ng} / \mathrm{ml}$ NIDDK-oPRL. The intra-assay CV for three plasma pools averaged $21 \%$.

\section{Data analysis}

Concentrations of LH and PRL below the limit of detection were assigned the value of assay sensitivity for data analysis and plotting. LH pulse detection was performed by means of the Munro software (Zaristow software, West Morham, Haddington, East Lothian EH41 4PD, Scotland), according to the method of Merriam \& Wachter (1982) (G parameters: $G 1=3 \cdot 78 ; G 2=2 \cdot 20$; $\mathrm{G} 3=1 \cdot 60 ; \quad \mathrm{G} 4=1 \cdot 24 ; \quad \mathrm{G} 5=0.93 ; \quad$ Baxter parameters: $\mathrm{b} 1=0 \cdot 07997 ; \mathrm{b} 2=0 \cdot 03 ; \mathrm{b} 3=0 \cdot 003) . \mathrm{LH}$ pulse frequency was evaluated by the inter-pulse interval (IPI).

The effects of the different pharmacological treatments on mean LH and PRL concentrations, and on LH pulsatility parameters (IPI and amplitude), were analyzed by repeated measure analysis of variance with SuperANOVA software (Abacus Concepts, Berkeley, CA, USA). Data from Experiment 1a and Experiment 2 were analyzed by a one-way ANOVA (within factor: dialysis periods) followed by least square means test (two-by-two comparisons). For Experiment $1 \mathrm{~b}$, data were analyzed by a two-way ANOVA (within factors: treatment ( $\alpha$ MPT alone, $\alpha$ MPT+SKF38393, $\alpha$ MPT+quinpirole) and dialysis period (control, drug infusion)); because each treatment was preceded by a 5 -h control period of Ringer perfusion, the effects of the analogs were tested through an interaction between treatment and dialysis period. In order to standardize variances, statistical analysis was performed after a $\log$ transformation of IPI and mean PRL concentration values.

\section{Results}

\section{Location of dialysis probes}

Histological examination of the probe location at the end of the experiments revealed that for Experiment 1a, five of seven ewes (Nos 1-5) had their probe accurately located within the ME (Fig. 2). The ewe No. 6 had its probe placed in the plane A28 of Richard stereotaxic atlas (Richard 1967), above the ME in the arcuate nucleus region, and ewe No. 7 had its probe located in the optic 

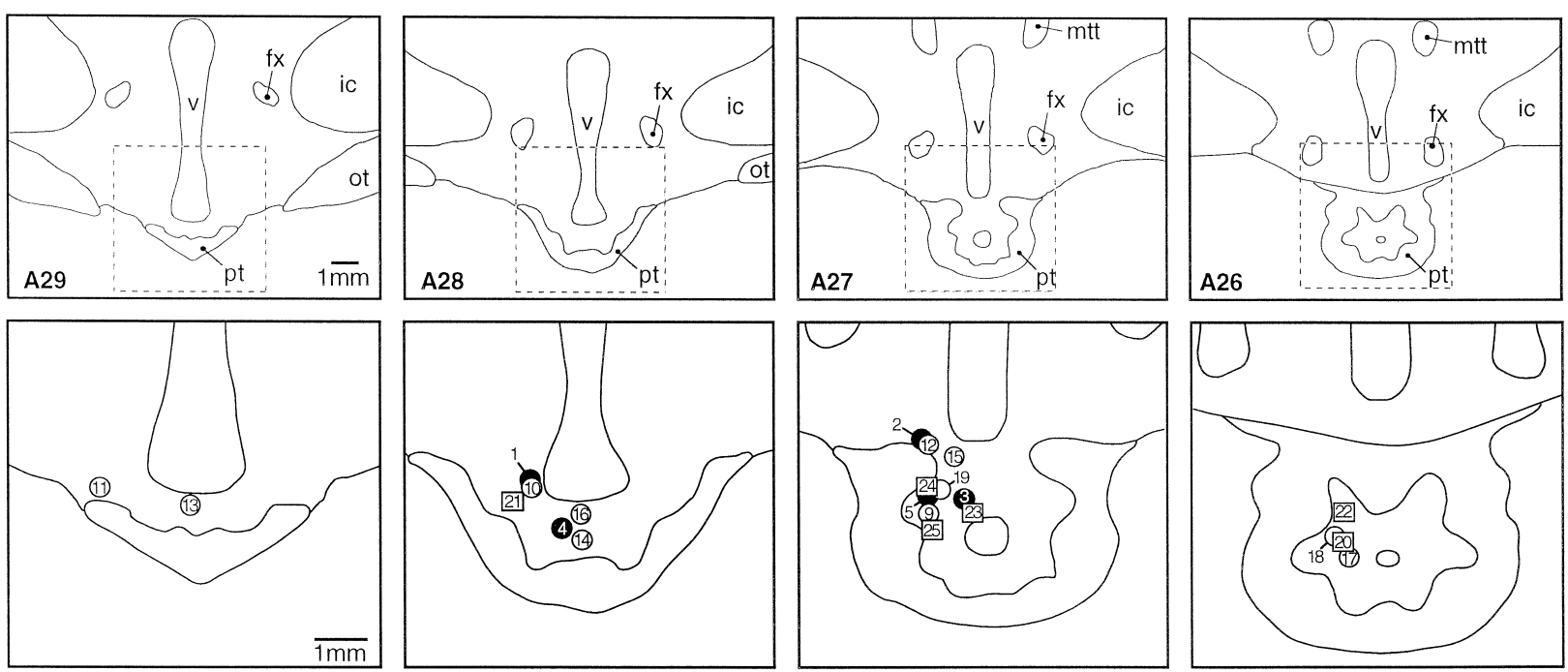

Figure 2 Location of the microdialysis probes within the median eminence. Top panels: Schematic sections of the mediobasal hypothalamus in four consecutive antero-posterior planes (A26-29), adapted from Richard (1967). fx, fornix; ic, internal capsule; mtt, mammillo-thalamic tract; ot, optic tract; pt, pars tuberalis; $v$, third ventricle. Bottom panels: Location of the dialysis probes (magnified view of the areas in top panels delimited with dotted lines). Numbered circles depict the location of the middle part of the $3 \mathrm{~mm}$ active membrane of the probe for each animal (with an angle of $6^{\circ}$ with respect to the sagittal plane). Black circles correspond to Experiment 1a (Nos 1-5), white circles to Experiment 1b (Nos 9-19) and white squares to Experiment 2 (Nos 20-25).

chiasma. For Experiment 1b, 11 of 12 ewes (Nos 9-19) had their probes accurately placed within the ME (Fig. 2). The remaining ewe (No. 8) had its probe located in plane A30 of Richard stereotaxic atlas, above the ME, in the area of the rostral part of the arcuate nucleus. For Experiment 2, all the six ewes had their probe accurately located in the ME (Fig. 2).

The three animals with their probes located outside ME were excluded from statistical analysis; consequently, analysis was for five animals for Experiment 1a, eleven for Experiment 1b, and six for Experiment 2.

\section{Effects of the pharmacological treatments on LH secretion}

Experiment 1a Individual profiles of LH secretion are presented in Fig. 3. Infusion of SKF38393 did not significantly affect mean LH concentrations and IPI compared with vehicle treatment, regardless of the dose (Fig. 4). Conversely, infusion of quinpirole significantly reduced mean LH concentration and increased IPI compared with vehicle and SKF38393. This effect depended on the dose, as the difference became significant only in period 3, corresponding to the highest dose of agonist $(P<0 \cdot 01$ for IPI and $P<0.05$ for mean LH concentration). No effect on pulse amplitude was found. In contrast to these five ewes with probes accurately located in the ME, which all showed an inhibition of $\mathrm{LH}$ secretion during treatment with the highest dose of quinpirole, no inhibition of LH secretion was found in the other two ewes with misplaced probes, particularly ewe No. 6 in which the probe was in the arcuate nucleus area (mean plasma LH during period 3: ewe No. 6, 6.0-8.7-6.4 ng/ml; ewe No. $7,7 \cdot 4-8 \cdot 8-7 \cdot 8 \mathrm{ng} / \mathrm{ml}$, Ringer-SKF38393-quinpirole, respectively).

Experiment 1b Individual profiles of $\mathrm{LH}$ secretion are presented in Fig. 5. A global interaction between treatment and period of dialysis was found $(P<0 \cdot 01$ for IPI and $P=0.001$ for mean LH concentration; Fig. 6). In two-by-two comparisons, no treatment $x$ dialysis period interaction was found between $\alpha \mathrm{MPT}$ alone and aMPT+SKF38393 treatments. Conversely, a significant treatment $\times$ dialysis period interaction was observed between $\alpha \mathrm{MPT}+$ quinpirole treatment and the other two treatments $(P<0 \cdot 05$ for both mean $\mathrm{LH}$ concentration and IPI). No effect on pulse amplitude was found (analysis on 10 animals, as one animal did not present any pulse during the control period). Because of the small relative amplitude of the effects of the different treatments and of their inter-individual variability in these 11 animals with probes placed correctly in the ME, the data of ewe No. 8, with misplaced probe, could not provide any pertinent insight about the relationship between probe placement and $\mathrm{LH}$ response.

Experiment 2 Individual profiles of $\mathrm{LH}$ secretion are presented in Fig. 7. Infusion of SCH23390 did not significantly affect mean LH concentration and IPI compared with vehicle treatment, regardless of the dose (Fig. 8). Conversely, infusion of sulpiride significantly 


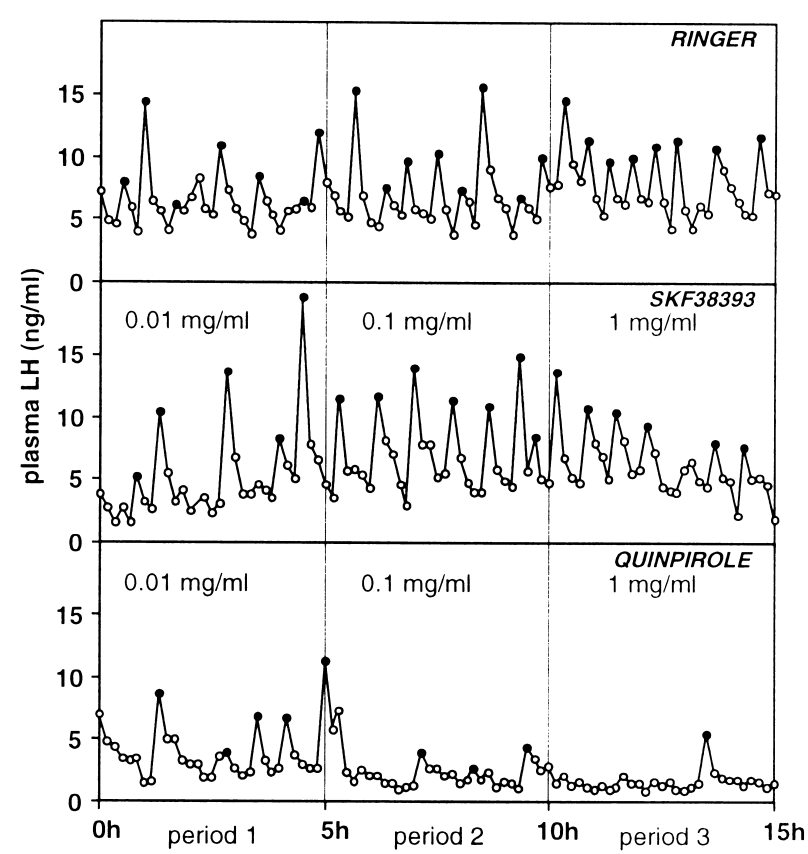

Figure 3 Experiment 1a. LH secretory profiles of ewe No. 3. Blood was collected every 10 min during the $15 \mathrm{~h}$ of dialysis. During the periods $0-5 \mathrm{~h}, 5-10 \mathrm{~h}$ and $10-15 \mathrm{~h}$, the doses of dopaminergic agonists (D1, SKF38393; D2, quinpirole) were 0.01, 0.1 and $1 \mathrm{mg} / \mathrm{ml}$, respectively. $\bullet$, Pulses identified by Munro algorithm.

decreased IPI compared with vehicle and SKF38393 treatments in the same period. This effect depended on the dose, as it became significant only in period 3 (highest dose; $P<0.05$ for IPI). Surprisingly, no difference was found in mean LH concentration. Careful observation of the individual $\mathrm{LH}$ profiles revealed that, during infusion of the highest dose of sulpiride, a biphasic response was observed: mean LH concentrations tended to increase, but this effect did not last and $\mathrm{LH}$ concentrations returned to baseline after about $3 \mathrm{~h}$ (Fig. 7). On the basis of this observation, analysis was also performed on mean $\mathrm{LH}$ concentration during the first $3 \mathrm{~h}$ of each treatment period. No difference was then found between vehicle and SCH23390 treatments, but, in contrast, sulpiride induced a significant increase in mean LH concentration at the highest dose $(P<0 \cdot 05 ;$ Fig. 8). Analysis of pulse amplitude was not performed because two animals did not present any pulse during at least one period.

\section{Effects of pharmacological treatments on $P R L$ concentrations}

Experiment 1a Infusion of SKF38393 did not significantly affect mean PRL concentration compared with vehicle treatment, regardless of the dose (Table 1). Conversely, infusion of quinpirole significantly reduced mean PRL concentration compared with vehicle and SKF38393. This effect depended on the dose, as the effect

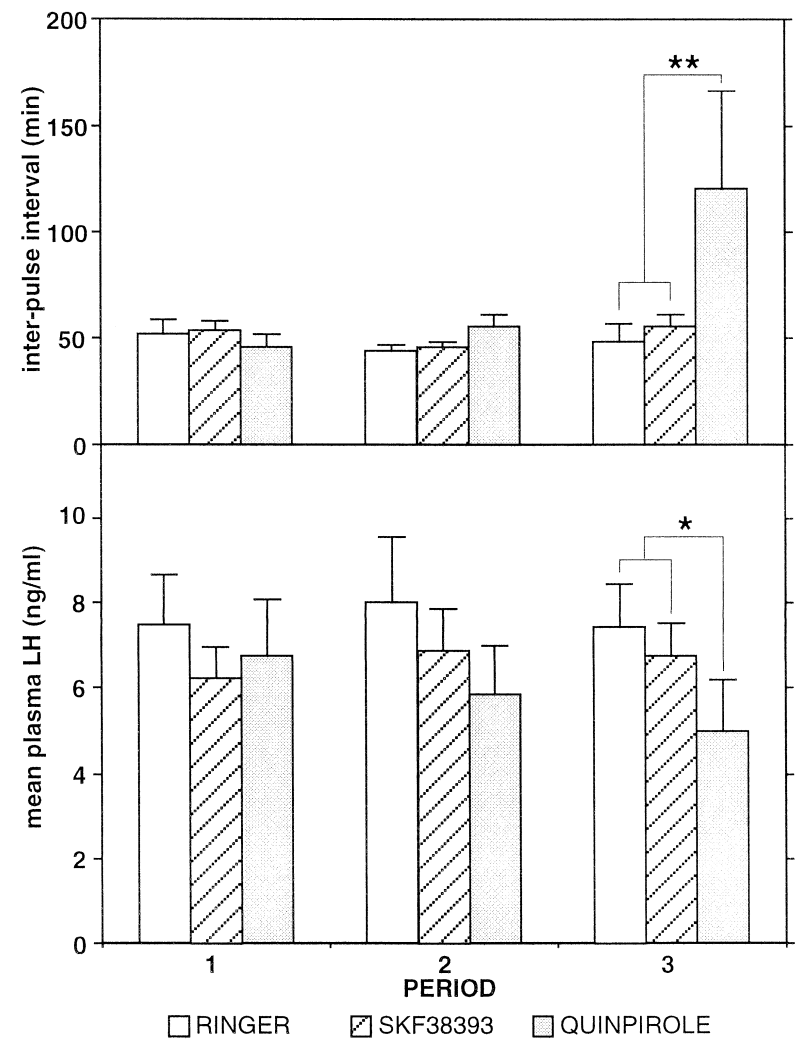

Figure 4 Experiment 1a. Effects of infusion in the ME of Ringer's lactate (vehicle), SKF38393 (D1 agonist) and quinpirole (D2 agonist) on mean ( \pm S.E.M.) LH inter-pulse interval and concentration in $\mathrm{OVX}+\mathrm{E}$ ewes after a 78 short-days exposure. At the end of periods 1 and 2, the dose of dopaminergic agonists was increased $(0 \cdot 01,0 \cdot 1$ and $1 \mathrm{mg} / \mathrm{ml}$ for periods 1,2 and 3 , respectively). ${ }^{*} P<0 \cdot 05,{ }^{*} P<0 \cdot 01 ; n=5$.

became significant in period $2(-47 \pm 5 \%$ compared with Ringer's lactate, $P<0 \cdot 05 ; \quad n=5)$ and in period 3 $(-54 \pm 6 \%, P<0 \cdot 01)$. In contrast to all other ewes, in ewe No. 6 (probe located in the arcuate nucleus region), SKF38393 induced a strong increase in mean PRL concentration (+181\% compared with Ringer's lactate, period 3 ) and quinpirole did not seem to induce a decrease $(+13 \%)$. In ewe No. 7 (probe located in the optic chiasma), no obvious effect of the different treatments was observed.

Experiment 1b Analysis of mean PRL concentration revealed an interaction between treatment and period of dialysis $(P<0 \cdot 05$; Table 1$)$. The effect of the treatment with $\alpha M P T+S K F 38393$ was significantly different from treatment with $\alpha \mathrm{MPT}$ alone (interaction treatment $\times$ dialysis period, $P<0 \cdot 05$ ), with a decrease in PRL concentration (Table 1). The effect of treatment with $\alpha \mathrm{MPT}+$ quinpirole was significantly different from the other two treatments (interaction treatment $\times$ dialysis 


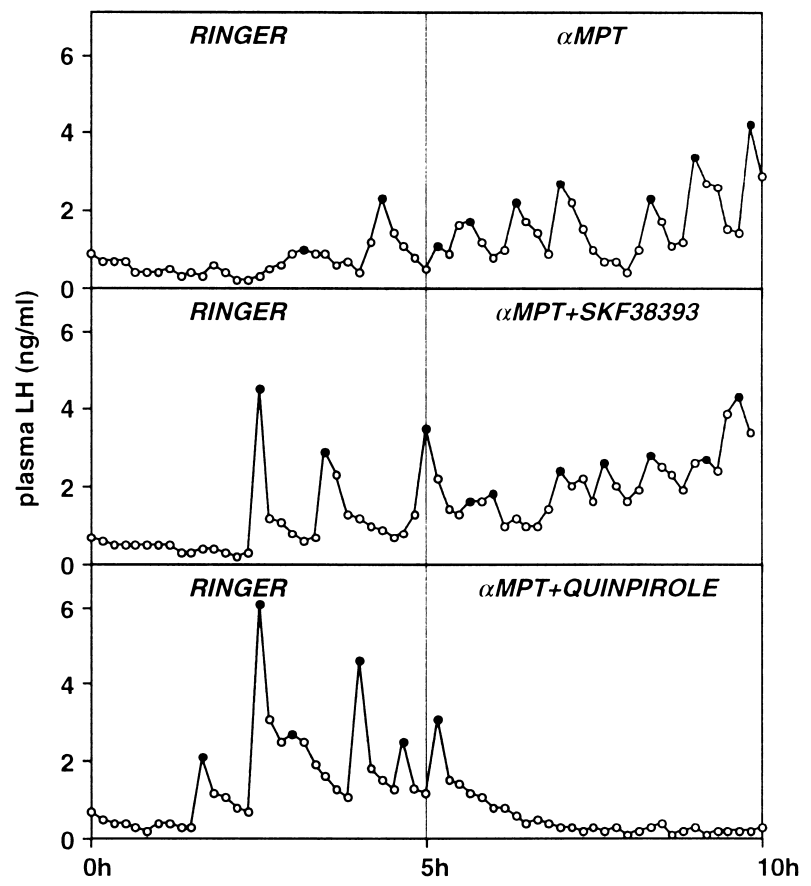

Figure 5 Experiment 1b. LH secretory profiles of ewe No. 10. Blood was collected every $10 \mathrm{~min}$ during the $10 \mathrm{~h}$ of dialysis. During the period $0-5 \mathrm{~h}$, only vehicle (Ringer's lactate) was infused. During the period 5-10 h, $\alpha$ MPT alone $(2 \mathrm{mg} / \mathrm{ml})$, $\alpha \mathrm{MPT}+\mathrm{SKF} 38393(1 \mathrm{mg} / \mathrm{ml})$ or $\alpha \mathrm{MPT}+$ quinpirole $(1 \mathrm{mg} / \mathrm{ml})$ were infused. ๑, Pulses identified by Munro algorithm.

period, $P<0 \cdot 01$ compared with both other treatments), with a important decrease in PRL concentration (Table 1). In ewe No. 8 (probe located in the rostral part of the arcuate nucleus region), a decrease in PRL concentrations was observed regardless of the treatment $(\alpha \mathrm{MPT}$ alone, $-32 \% ; \alpha \mathrm{MPT}+\mathrm{SKF} 38393,-64 \% ; \alpha \mathrm{MPT}+$ quinpirole, $-41 \%$ compared with control period).

Experiment 2 Infusion of SCH23390 did not significantly affect mean PRL concentration compared with vehicle treatment, whatever the dose (Table 1). Conversely, infusion of sulpiride significantly increased mean PRL concentration compared with vehicle and $\mathrm{SCH} 23390$. This effect depended on the dose, as it became significant in period $2(+64 \pm 23 \%$ compared with Ringer's lactate, $P<0 \cdot 05 ; n=6)$, and was dramatically expressed in period $3(+197 \pm 50 \%, P<0 \cdot 001)$, corresponding to the highest dose of sulpiride.

\section{Discussion}

The present study, carried out in conditions in which the critical role of the ME dopaminergic terminals has been shown (Bertrand et al. 1998), demonstrates that infusion of a D2-like specific agonist in the ME of long-day exposed

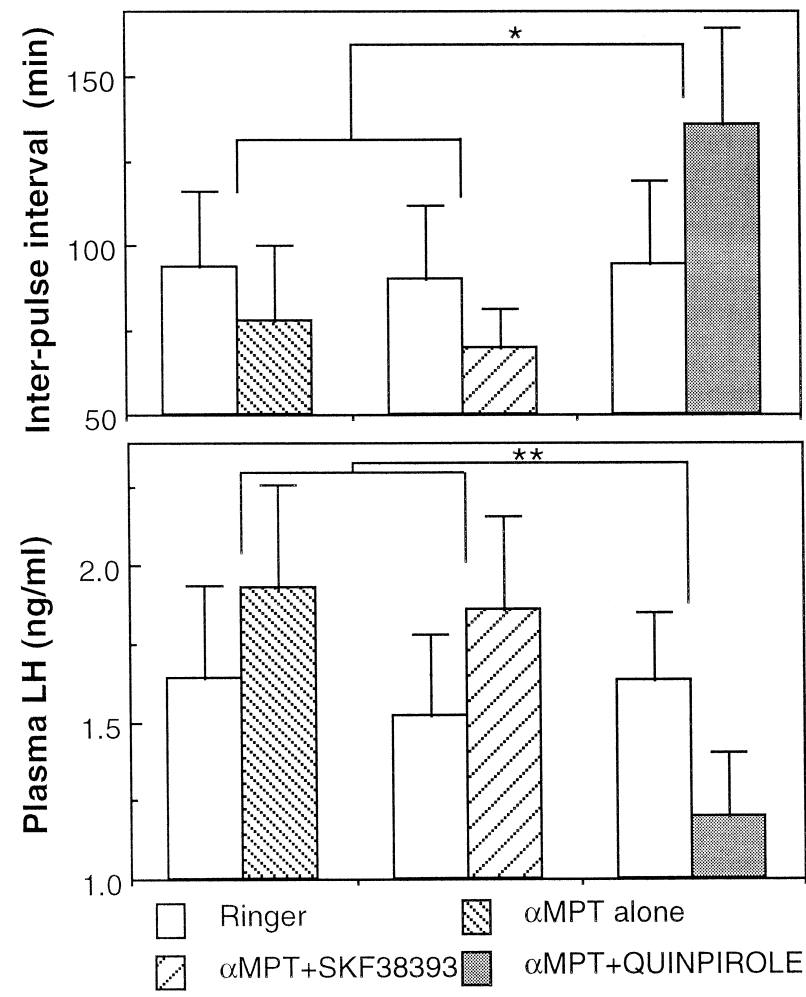

Figure 6 Experiment $1 \mathrm{~b}$. Comparison of the effects of infusion in the ME of $\alpha$ MPT alone $(2 \mathrm{mg} / \mathrm{ml}), \alpha M P T+S K F 38393(1 \mathrm{mg} / \mathrm{ml})$ and $\alpha \mathrm{MPT}+$ quinpirole $(1 \mathrm{mg} / \mathrm{ml})$ on mean $( \pm$ S.E.M.) $\mathrm{LH}$ inter-pulse interval and concentration in OVX $+\mathrm{E}$ ewes after a 33 long-days exposure. Significant interaction between treatment and dialysis period: ${ }^{*} P<0 \cdot 05,{ }^{*} P<0 \cdot 01 ; n=11$.

$\mathrm{OVX}+\mathrm{E}$ ewes can restore the inhibition of $\mathrm{LH}$ secretion removed by blockade of dopamine synthesis. Furthermore, it shows that infusion of a D2-like specific antagonist can disinhibit LH secretion. The D2-like analogs always induced a change in LH pulse frequency, suggesting that they acted at the ME level on LHRH pulsatile secretion, rather than directly at the pituitary level. The same treatments with D1-like specific analogs did not produce any of these effects. Altogether, these results strongly suggest that the initiation of long-day-induced inhibition of LHRH (and consequently LH) secretion by dopamine in the ME occurs through D2-like dopaminergic receptors, not through D1-like ones.

Our results confirm and extend previous experiments in sheep suggesting that dopamine acts through D2-like dopaminergic receptors for the inhibition of LH secretion. For example, i.v. injection of pimozide, a D2-like antagonist, stimulated $\mathrm{LH}$ secretion in intact and $\mathrm{OVX}+\mathrm{E}$ ewes during the anestrus season (Meyer \& Goodman 1985, 1986). In the ram, s.c. injection of sulpiride during long days stimulated LH secretion, whereas s.c. injection of bromocriptine, a D2-like agonist, reduced LH secretion 


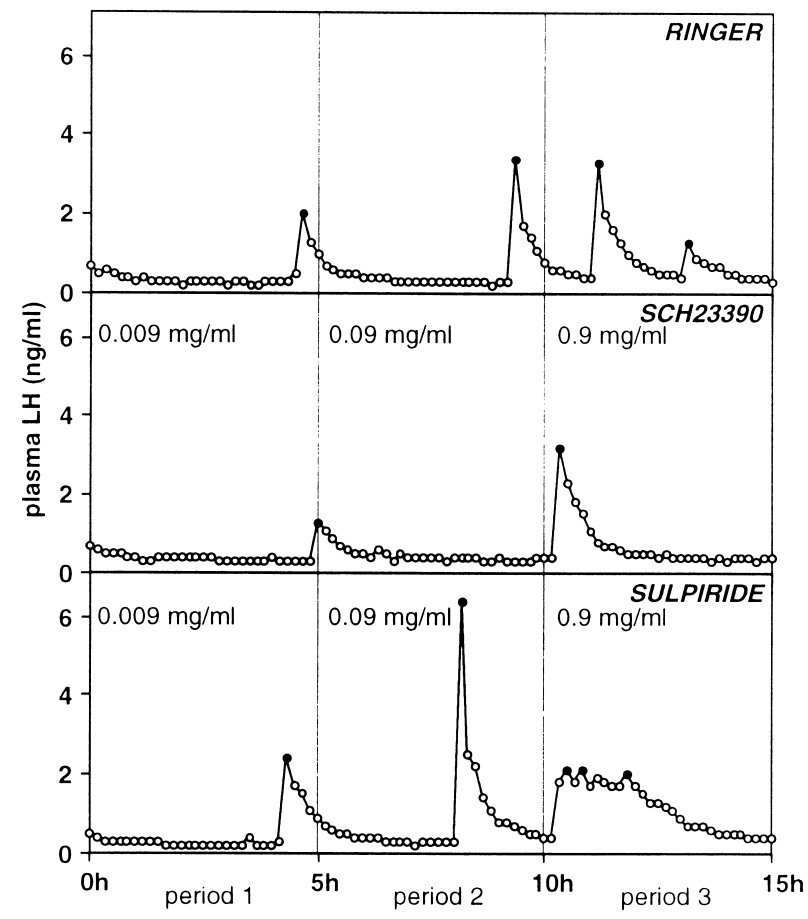

Figure 7 Experiment 2. LH secretory profiles of ewe No. 24. Blood was collected every 10 min during the $15 \mathrm{~h}$ of dialysis. During the periods $0-5 \mathrm{~h}, 5-10 \mathrm{~h}$ and $10-15 \mathrm{~h}$, the doses of dopaminergic antagonists (D1, SCH23390; D2, sulpiride) were $0.009,0.09$ and $0.9 \mathrm{mg} / \mathrm{ml}$, respectively. - , Pulses identified by Munro algorithm.

under short days (Tortonese \& Lincoln 1994). Intracerebroventricular administration of quinpirole reduced $\mathrm{LH}$ pulse frequency in $\mathrm{OVX}+\mathrm{E}$ ewes during the breeding season, whereas the same treatment with SKF38393 did not have any effect on LH secretion (Curlewis et al. 1991). Conversely, i.v. injection of pimozide tends to increase $\mathrm{LH}$ pulse frequency in $\mathrm{OVX}+\mathrm{E}$ ewes during anestrus, while SCH23390 has no effect (Curlewis et al. 1991). Moreover, placement of pimozide microimplants in the ME in anestrous ewes stimulated LH secretion (Havern et al. 1991), whereas local injection of quinpirole in the ME-arcuate nucleus region inhibited $\mathrm{LH}$ secretion in OVX ewes (Anderson et al. 1997). Our study complements these results, by providing the first comparison of the effects of local delivery of D1-like and D2-like analogs in the ME. Furthermore, the role of dopamine in the ME may vary during the time course of the long-day-induced inhibition of LH secretion (Bertrand et al. 1998). Importantly, our two main experiments (Experiment $1 \mathrm{~b}$ and 2) were carried out under photoperiodic conditions (exposure to 30-50 long days) under which it has been shown that an increased activity of ME dopaminergic terminals is critical for the inhibition of $\mathrm{LH}$ secretion (Bertrand et al. 1998, Viguié et al. 1998). Our results therefore demonstrate that the initiation of long-day-

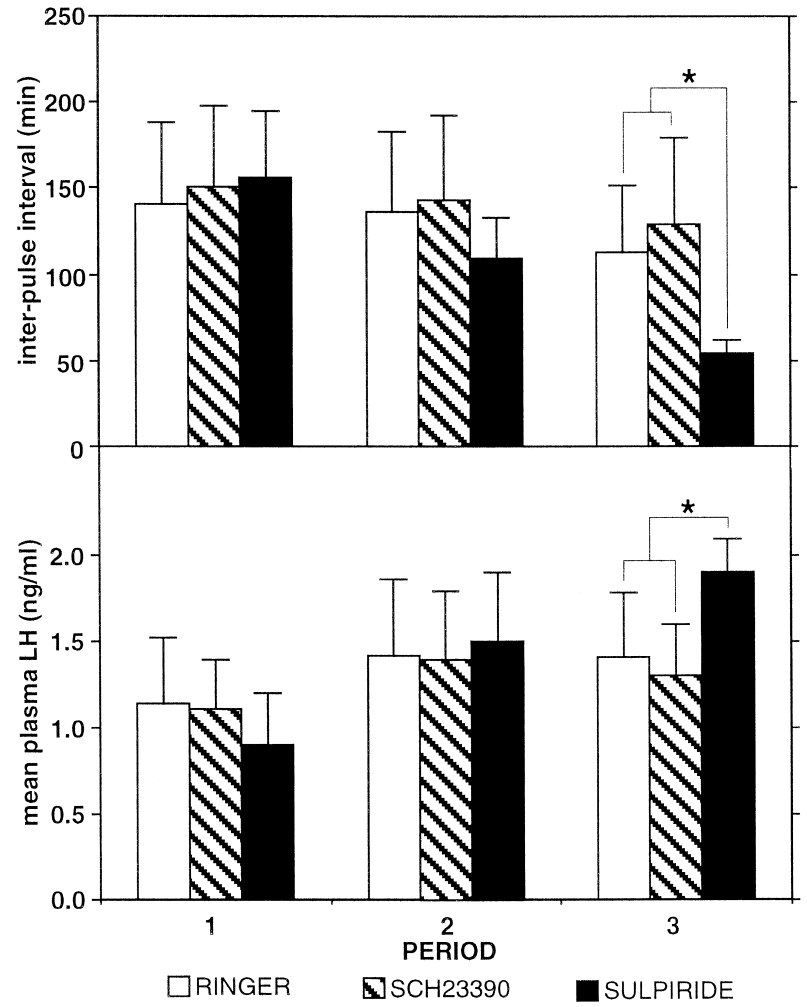

Figure 8 Experiment 2. Effects of infusion in the ME of Ringer's lactate (vehicle), SCH23390 (D1 antagonist) and sulpiride (D2 antagonist) on mean ( \pm S.E.M.) LH inter-pulse interval and concentration in $\mathrm{OVX}+\mathrm{E}$ ewes after a 49 long-days exposure. At the end of periods 1 and 2, the dose of dopaminergic antagonists was increased $(0.009,0.09$ and $0.9 \mathrm{mg} / \mathrm{ml}$ for periods 1,2 and 3 , respectively). Mean $\mathrm{LH}$ concentration was calculated on the first $3 \mathrm{~h}$ of each period (see Results for explanation). ${ }^{*} P<0 \cdot 05 ; n=6$.

induced inhibition of $\mathrm{LHRH}$, and consequently of $\mathrm{LH}$, secretion by dopamine in the ME is mediated by D2-like, not D1-like, dopaminergic receptors.

In Experiment 2, infusion of sulpiride in the highest dose induced an increase in LH secretion, but this effect did not last throughout the 5 -h infusion period. A biphasic response characterized by a rapid increase in $\mathrm{LH}$ pulse frequency and mean levels, and by a return to basal levels, was observed. As LHRH secretion was not measured directly in this experiment, it is difficult to know whether the observed changes in $\mathrm{LH}$ secretion reflect those in LHRH secretion. It is possible that the effect of sulpiride on LHRH secretion was characterized by the induction of a short-lasting high-frequency release, followed by a return to baseline. Alternatively, the stimulation of LHRH release may have been maintained for a longer time, but have led to a decrease of the pituitary responsiveness to LHRH. Indeed, pituitary desensitization was described in vivo and in vitro after continuous infusion or highfrequency delivery (more than 3 pulses/h) of LHRH 
Table 1 Effects of D1-like and D2-like analogs on PRL secretion. For the Pilot experiment and Experiment 2, from period 1 to 3, increasing doses of drugs were infused $(0 \cdot 01,0 \cdot 1$ and $1 \mathrm{mg} / \mathrm{ml} ; 0.009 ; 0.09$ and $0.9 \mathrm{mg} / \mathrm{ml}$, respectively). For Experiment 1, Ringer's lactate was infused during the control period and drugs were infused during the treatment period ( $\alpha$ MPT $2 \mathrm{mg} / \mathrm{ml}$; SKF38393 and quinpirole $1 \mathrm{mg} / \mathrm{ml}$ )

\begin{tabular}{|c|c|c|c|}
\hline & \multicolumn{3}{|c|}{ PRL concentration $(\mathrm{ng} / \mathrm{ml})$} \\
\hline & Period 1 & Period 2 & Period 3 \\
\hline \multicolumn{4}{|l|}{ Experiment 1a $(n=5)$} \\
\hline Ringer's lactate & $33 \pm 7^{a}$ & $34 \pm 6^{a}$ & $34 \pm 5^{\mathrm{a}}$ \\
\hline SKF38393 & $39 \pm 5^{a}$ & $33 \pm 5^{a}$ & $36 \pm 6^{a}$ \\
\hline \multirow[t]{2}{*}{ Quinpirole } & $30 \pm 3^{\mathrm{a}}$ & $17 \pm 3^{b}$ & $15 \pm 1^{b}$ \\
\hline & Control period & Treatment period & Difference (\%) \\
\hline \multicolumn{4}{|l|}{ Experiment $\mathbf{1 b}(n=11)$} \\
\hline$\alpha \mathrm{MPT}$ alone & $147 \pm 17$ & $144 \pm 17$ & $+3 \pm 10^{\mathrm{a}}$ \\
\hline$\alpha \mathrm{MPT}+\mathrm{SKF} 38393$ & $170 \pm 18$ & $128 \pm 13$ & $-18 \pm 9^{b}$ \\
\hline \multirow[t]{2}{*}{$\alpha \mathrm{MPT}+$ Quinpirole } & $143 \pm 13$ & $79 \pm 13$ & $-39 \pm 14^{c}$ \\
\hline & Period 1 & Period 2 & Period 3 \\
\hline \multicolumn{4}{|l|}{ Experiment $2(n=6)$} \\
\hline Ringer's lactate & $111 \pm 16^{\mathrm{a}}$ & $135 \pm 39^{\mathrm{a}}$ & $120 \pm 24^{\mathrm{a}}$ \\
\hline $\mathrm{SCH} 23390$ & $91 \pm 11^{\mathrm{a}}$ & $102 \pm 10^{\mathrm{a}}$ & $111 \pm 15^{\mathrm{a}}$ \\
\hline Sulpiride & $129 \pm 19^{\mathrm{ab}}$ & $205 \pm 46^{b}$ & $341 \pm 66^{b}$ \\
\hline
\end{tabular}

In each experiment, significant differences are indicated by differing superscript letters.

(McIntosh \& McIntosh 1983, Baird et al. 1984, Kamel et al. 1987). For instance, treatment of perifused pituitary cells with LHRH, as given one 2-min pulse every $16 \mathrm{~min}$, caused an initial important release of LH, followed by a decrease within 2-3 h (McIntosh \& McIntosh 1983). It is to be noted that, in Experiment 2 during the initial 2-3 h of treatment with the highest dose of sulpiride, high concentrations of LH with low-amplitude pulses suggestive of a high LHRH frequency were found, and it is likely that $\mathrm{LH}$ pulses were poorly detected in this situation. Regardless of the explanation for this biphasic effect, the initial stimulation of $\mathrm{LH}$ secretion during this period, indicative of a stimulation of LHRH secretion, which did not occur with the SCH23390, is in favor of the implication of D2-like receptors.

In our studies, large effects of D2-like analogs were found on PRL secretion. These effects have been described previously (Lincoln \& Tortonese 1995, Anderson et al. 1997) and may account for a local effect on neurons located in the ME region, or for a transport of the drugs by hypophysial portal blood towards the anterior pituitary, where dopamine can act on lactotrophs through D2-like receptors to inhibit PRL secretion (Ben-Jonathan 1985, Anderson et al. 1997). However, it is noteworthy that, in ewes with probes located accurately in the ME, no stimulatory effect of SKF38393 nor inhibitory effect of SCH23390 on PRL secretion were found. These results contrast with the demonstration that a local infusion of the same D1-like antagonist SCH23390, in the ventromedial hypothalamic nucleus inhibited PRL secretion (Curlewis et al. 1995a). This nucleus, in which a high density of D1-like receptors is found (Colthorpe \& Curlewis 1996), is believed to be involved in a stimulatory pathway of PRL secretion in sheep (Curlewis et al. 1995b). Interestingly, in Experiment 1a, a strong stimulation of PRL secretion was observed for ewe No. 6, after infusion of the D1-like agonist, SKF38393, in the arcuate nucleus region. This result is not surprising, because of the proximity of the arcuate nucleus to the ventromedial hypothalamic nucleus. However, in Experiment $1 \mathrm{~b}$, no effect of SKF38393 on PRL secretion was found for ewe No. 8, in which the probe was also located in the arcuate nucleus region, but much more rostrally than that in ewe No. 6 . This result is consistent with those of Curlewis et al. (1995a), who found SCH23390 to be ineffective to inhibit PRL secretion when delivered in the rostral part of the ventromedial hypothalamic nucleus. Taking into account the results on PRL secretion of ewes No. 6 and No. 8, and because of the proximity of the ventromedial hypothalamic nucleus to the ME and to the third ventricle, the absence of stimulatory and inhibitory effects of D1-like agonist and antagonist, respectively, indicates that diffusion of the drugs to other hypothalamic areas was very limited in our experiments. It also indicates that, despite the proximity of the ME to the third ventricle, diffusion toward this cavity was limited, and that the dilution of the drugs in the cerebrospinal fluid prevented them reaching target sites in other hypothalamic areas close to the 
ventricle in amounts sufficient to produce any effect. These conclusions are reinforced by observations of $\mathrm{LH}$ secretion made in animals with misplaced probes. In these animals, infusion of the D2-like analogs in the arcuate nucleus region (ewes No. 6 and No. 8) or in the optic chiasma (ewe No. 7) produced effects on LH secretion different from those observed when infusion was made in the ME. Therefore, the changes in LH secretion caused by the D2-like analogs most probably resulted from an action limited to the ME region.

As strong effects of the D2-like analogs on PRL secretion were observed concomitantly to the effects on LH secretion, it could be hypothesized that the changes in $\mathrm{LH}$ secretion were the consequence of those in PRL secretion. This hypothesis is very unlikely to be valid. Indeed, it has been shown in several animal species that hyperprolactinemia was responsible for inhibition of LH secretion (Evans et al. 1982) whereas, in our experiments, changes in LH and PRL secretion were positively correlated after the D2-like analog treatments. Moreover, findings from several experiments in the sheep suggest that PRL is not a modulator of LH secretion. For example, active immunization against PRL, which results in an important decrease in plasma PRL concentrations, does not affect plasma LH concentration in the ram (Ohlson et al. 1981). Also, increased plasma PRL concentrations as a result of hypothalamo-neurohypophysial tract disruption did not change plasma $\mathrm{LH}$ concentrations in the ewe (Thomas et al. 1989). Moreover, the inverse relationship between PRL concentrations and reproductive activity normally seen during the year is not critical to the changes in seasonal reproductive activity (Worthy \& Haresign 1983, Worthy et al. 1985).

No data exist in the literature regarding the presence of D2-like receptors in the ME of the ewe. A binding study by Cronin \& Weiner (1979) suggested the presence of putative dopaminergic receptors in the stalk-ME of the ewe. However, this study must be interpreted cautiously, as it was carried out with $\left[{ }^{3} \mathrm{H}\right]$ spiperone, a ligand which has been demonstrated, since then, also to bind serotoninergic receptors (Leysen 1981). Concerning D1-like receptors, a binding study with $\left[{ }^{125} \mathrm{I}\right] \mathrm{SCH} 23982$, a D1like specific ligand, did not demonstrate any specific binding in the ME and the arcuate nucleus, in contrast to the ventromedial hypothalamic nucleus (Colthorpe \& Curlewis 1996). Therefore, the results of our study raise the question of the presence of D2-like dopaminergic receptors in the ME. This could be resolved by binding or autoradiographic studies with an appropriate ligand, such as $\left[{ }^{125} \mathrm{I}\right]$ iodosulpride. The question also remains whether dopamine in the ME acts directly on LHRH terminals, or if there exist intermediate neurons relaying dopamine action. No evidence exists for the presence of dopamine receptors on LHRH neurons, so the implication of an interneuronal system cannot be excluded. Nevertheless, a direct action of dopamine on LHRH terminals is suggested by the observation of axo-axonic synaptic contacts between dopaminergic and LHRH terminals within the ME (Kuljis \& Advis 1989). Such organization is also found in rats (Ajika 1979, Ugrumov et al. 1989) and in hens (Contijoch et al. 1992). The ability of dopamine to act directly on LHRH neurons could be determined, for instance, by assessing the presence of D2-like receptors on LHRH neurons by immunocytochemistry at the electron microscopic level, or by testing the action of dopamine in vitro on cultured LHRH neurons.

In conclusion, this study provides the first comparison of the effects on LH secretion of D1-like and D2-like dopaminergic analogs in the ME, where a critical step for the establishment of long-day-induced inhibition of LH secretion takes place. Our results strongly suggest that the dopamine inhibition of LHRH secretion in the ME, critical for the establishment of the long-day-inhibitory effects on LH secretion, is mediated by D2-like, not D1-like, dopaminergic receptors. As a possible interaction between dopamine and LHRH terminals in the ME has been suggested on the basis of anatomical data (Kuljis \& Advis 1989), our study enables the use of adequate probes to resolve the question of a direct regulation of LHRH secretion by dopamine in this structure.

\section{Acknowledgements}

The authors thank Drs P Chemineau and D C Skinner for comments on the manuscript; Ms F Maurice-Mandon, K Courvoisier, A Daveau, Mr C Gauthier, G Duarte and Dr L Zarazaga for assistance with the experimentation; Mr G Durand, F Dupont and F Paulmier for animal care.

F Bertrand was supported by a $\mathrm{PhD}$ grant from the Ministère de l'Education Nationale, de la Recherche et de la Technologie.

Findings of this study were presented in preliminary form at the 'XXVeme Colloque de la Société de Neuroendocrinologie Expérimentale', Strasbourg, France, 27-28 September 1996 and '3eme Colloque de la Société des Neurosciences', Bordeaux, France, 25-28 May 1997.

\section{References}

Ajika K 1979 Simultaneous localization of LHRH and catecholamines in rat hypothalamus. Journal of Anatomy 128 331-347.

Anderson ST, Sawangjaroen K \& Curlewis JD 1997 A method for drug infusion into the lateral median eminence and arcuate nucleus of sheep. Journal of Neuroscience Methods 71 169-176.

Baird CJ, Tharandt L \& Tamarkin L 1984 Regulation of luteinizing hormone release by pulsatile and continuous administration of gonadotropin-releasing hormone to superfused rat and hamster pituitary cells. Endocrinology 114 1041-1047.

Ben-Jonathan N 1985 Dopamine: a prolactin-inhibiting hormone. Endocrine Reviews 6 564-589.

Bertrand F, Viguié C, Picard S \& Malpaux B 1998 Median eminence dopaminergic activation is critical for the early long-day inhibition of luteinizing hormone secretion in the ewe. Endocrinology 139 5094-5102. 
Colthorpe KL \& Curlewis JD 1996 Localization and characterization of dopamine D1 receptors in sheep hypothalamus and striatum. Journal of Neuroendocrinology 8 561-568.

Contijoch AM, Gonzalez C, Singh HN, Malamed S, Troncoso S \& Advis JP 1992 Dopaminergic regulation of luteinizing hormonereleasing hormone release at the median eminence level: immunocytochemical and physiological evidence in hens. Neuroendocrinology 55 290-300.

Cronin MJ \& Weiner RI $1979\left[{ }^{3} \mathrm{H}\right]$ Spiroperidol (spiperone) binding to a putative dopamine receptor in sheep and steer pituitary and stalk median eminence. Endocrinology 104 307-312.

Curlewis JD 1992 Seasonal prolactin secretion and its role in seasonal reproduction: a review. Reproduction Fertility and Development 4 $1-23$.

Curlewis JD, Naylor AM \& McNeilly AS 1991 Evaluation of a possible role of dopamine D1 and D2 receptors in the steroiddependent suppression of luteinizing hormone secretion in the seasonally anoestrus ewe. Journal of Neuroendocrinology 3 387-391.

Curlewis JD, Thiéry JC \& Malpaux B 1995a Effect of hypothalamic infusion of a dopamine D1 receptor antagonist on prolactin secretion in the ewe. Brain Research 697 48-52.

Curlewis JD, Thiéry JC \& Malpaux B 1995 b Evidence for dopamine D1 receptor-mediated stimulation of prolactin secretion in ewes under long day length. Journal of Reproduction and Fertility Supplement 49 539-543.

Evans WS, Cronin MJ \& Thorner MO 1982 Hypogonadism in hyperprolactinemia: proposed mechanisms. In Frontiers in Neuroendocrinology, vol 7, pp 77-122. Eds WF Ganong \& L Martini. New York: Raven Press.

Havern RL, Whisnant CS \& Goodman RL 1991 Hypothalamic sites of catecholamine inhibition of luteinizing hormone in the anestrous ewe. Biology of Reproduction 44 476-482.

Havern RL, Whisnant CS \& Goodman RL 1994 Dopaminergic structures in the ovine hypothalamus mediating estradiol negative feed-back in anestrous ewes. Endocrinology 134 1905-1914.

Kamel F, Balz JA, Kubajak CL \& Schneider VA 1987 Effects of luteinizing hormone (LH)-releasing hormone pulse amplitude and frequency on $\mathrm{LH}$ secretion by perifused rat anterior pituitary cells. Endocrinology 120 1644-1650.

Kann G 1971 Dosage radioimmunologique de la prolactine plasmatique chez les ovins. Comptes Rendus de l'Académie des Sciences III 272 28082811.

Karsch FJ, Bittman EL, Foster DL, Goodman RL, Legan SJ \& Robinson JE 1984 Neuroendocrine basis of seasonal reproduction. Recent Progress in Hormone Research 40 185-232.

Kebabian JW \& Calne DB 1979 Multiple receptors for dopamine. Nature 277 93-96.

Klüver A \& Barrera E 1953 A method of combining staining of cells and fibers in the nervous system. Journal of Neuropathology and Clinical Neurology 12 400-403.

Kuljis RO \& Advis JP 1989 Immunocytochemical and physiological evidence of a synapse between dopamine- and luteinizing hormone releasing hormone-containing neurons in the ewe median eminence. Endocrinology 124 1579-1581.

Legan SJ \& Karsch FJ 1980 Photoperiodic control of seasonal breeding in ewes: modulation of the negative feedback action of estradiol. Biology of Reproduction 23 1061-1068.

Legan SJ, Karsch FJ \& Foster DL 1977 The endocrine control of seasonal reproductive function in the ewe: a marked change in response to the negative feedback action of estradiol on luteinizing hormone secretion. Endocrinology 101 818-824.

Leysen JE 1981 Serotoninergic receptors in brain tissue: properties and identification of various $3 \mathrm{H}$-ligand binding sites in vitro. Journal of Physiology 77 351-362.

Lincoln GA \& Tortonese DJ 1995 Does melatonin act on dopaminergic pathways in the mediobasal hypothalamus to mediate effects of photoperiod on prolactin secretion in the ram? Neuroendocrinology 62 425-433.
McIntosh RP \& McIntosh JE 1983 Influence of the characteristics of pulses of gonadotrophin releasing hormone on the dynamics of luteinizing hormone release from perifused sheep pituitary cells. Journal of Endocrinology 98 411-421.

Merriam GR \& Wachter KW 1982 Algorithms for the study of episodic hormone secretion. American Journal of Physiology 2434 E310-E318.

Meyer SL \& Goodman RL 1985 Neurotransmitters involved in mediating the steroid-dependent suppression of pulsatile luteinizing hormone secretion in anestrous ewes: effects of receptor antagonists. Endocrinology 116 2054-2061.

Meyer SL \& Goodman RL 1986 Separate neural systems mediate the steroid-dependent and steroid-independent suppression of tonic luteinizing hormone secretion in the anestrous ewe. Biology of Reproduction 35 562-571.

Montgomery GW, Martin GB \& Pelletier J 1985 Changes in pulsatile LH secretion after ovariectomy in Ile-de-France ewes in two seasons. Journal of Reproduction and Fertility 73 173-183.

Ohlson DL, Spicer LJ \& Davis SL 1981 Use of active immunization against prolactin to study the influence of prolactin on growth and reproduction in the ram. Journal of Animal Science 52 1350-1359.

Pelletier J, Kann J, Dolais J \& Rosselin G 1968 Dosage radioimmunologique de l'hormone lutéinisante plasmatique chez le mouton. Mise au point de la technique de dosage. Comptes Rendus de l'Académie des Sciences III 266 2291-2294.

Richard P 1967 Atlas Stéréotaxique du Cerveau de Brebis, pp 84. Paris, France: INRA Editions.

Robinson TE \& Whishaw IQ 1988 Normalization of extracellular dopamine in striatum following recovery from a partial 6-OHDA lesion of the substantia nigra: a microdialysis study in freely moving rats. Brain Research 450 209-224.

Robinson JE, Kendrick KM \& Lambart CE 1991 Changes in the release of GABA and catecholamines in the preoptic/septal prior to and during the preovulatory surge of luteinizing hormone in the ewe. Journal of Neuroendocrinology 3 393-399.

Thiéry JC 1991 Monoamine content of the stalk-median eminence and hypothalamus in adult female sheep as affected by daylength. Journal of Neuroendocrinology 3 407-411.

Thiéry JC, Martin GB, Tillet Y, Caldani M, Quentin M, Jamain C \& Ravault JP 1989 Role of hypothalamic catecholamines in the regulation of luteinizing hormone and prolactin secretion in the ewe during seasonal anoestrus. Neuroendocrinology 49 80-87.

Thimonier J, Ravault JP \& Ortavant R 1978 Plasma prolactin variations and cyclic ovarian activity in ewes submitted to different light regimens. Annales de Biologie Animale Biochimie Biophysique 18 1229-1235.

Thomas GB, Cummins JT, Doughton BW, Griffin N, Smythe GA, Gleeson RM \& Clarke IJ 1989 Direct pituitary inhibition of prolactin secretion by dopamine and noradrenaline in sheep. Journal of Endocrinology 123 393-402.

Tillet Y \& Thibault J 1989 Catecholamine-containing neurons in the sheep brainstem and diencephalon: immunohistochemical study with tyrosine hydroxylase TH and dopamine- $\beta$-hydroxylase DBH antibodies. Journal of Comparative Neurology 290 69-104.

Tortonese DJ \& Lincoln GA 1994 Photoperiodic modulation of the dopaminergic control of pulsatile LH secretion in sheep. Journal of Endocrinology 143 25-32.

Ugrumov M, Hisano S \& Daikoku S 1989 Topographic relations between tyrosine hydroxylase- and luteinizing hormone-releasing hormone-immunoreactive fibers in the median eminence of adult rats. Neuroscience Letters 102 159-164.

Viguié C, Thibault J, Thiéry JC, Tillet Y \& Malpaux B 1996 Photoperiodic modulation of monoamines and amino-acids involved in the control of prolactin and LH secretion in the ewe: evidence for a regulation of tyrosine hydroxylase activity. Journal of Neuroendocrinology 8 465-474.

Viguié C, Thibault J, Thiéry JC, Tillet Y \& Malpaux B 1997 Characterization of short day-induced decrease in median eminence 
tyrosine hydroxylase activity in the ewe: temporal relationship to the changes in luteinizing hormone and prolactin secretion and short-day like effect of melatonin. Endocrinology 138 499-506.

Viguié C, Picard S, Thiéry JC \& Malpaux B 1998 Blockade of tyrosine hydroxylase activity in the median eminence partially reverses the long day-induced inhibition of pulsatile LH secretion in the ewe. Journal of Neuroendocrinology 10 551-558.

Worthy K \& Haresign W 1983 Evidence that the onset of seasonal anoestrus in the ewe may be independent of increasing prolactin concentrations and daylength. Journal of Reproduction and Fertility 69 $41-48$.

Worthy K, Haresign W, Dodson S, McLeod BJ, Foxcroft GR \& Haynes NB 1985 Evidence that the onset of the breeding season in the ewe may be independent of decreasing plasma prolactin concentrations. Journal of Reproduction and Fertility 75 237-246.

Received 8 March 1999
Accepted 23 June 1999 